Gut, 1972, 13, 528-534

\title{
The effects of humoral agents on the myoelectrical activity of the terminal ileum
}

\author{
W. E. WATERFALl: B. H. BROWN, H. L. DUThie, AND G. E. Whittaker \\ From the University Department of Surgery and Regional Medical Physics Department, Sheffield
}

SUMMARY Electrical and motor activities of the terminal ileum have been recorded in 25 patients with a permanent ileostomy. Records made within a week of formation of the ileostomy show an increased motor activity which is significantly reduced after four weeks. Intravenous infusion of gastrin, $1 \mu \mathrm{g} / \mathrm{kg}-\mathrm{hr}$, was accompanied by a significant increase in action potentials and in the percentage motility. Conversely, secretin $1 \mathrm{unit} / \mathrm{kg}$-hr was associated with a decrease in action potentials and in percentage motor activity.

Small bowel studies in the conscious human subject are difficult because of inaccessibility. Motility has been measured by means of intubation, by telemetering capsules, or by radioopaque markers. Little information is available on the electrical activity of this area. An established ileostomy provides an opportunity for such study and it has been reported by Daniel, Wachter, Honour, and Bogoch (1958) in two subjects. We have extended these findings in a group of 25 patients.

\section{Method}

In 25 patients who had had the large bowel removed for granulomatous disease or ulcerative colitis, electrical activity and motility waves of the small bowel were recorded with a probe inserted into the terminal ileum. The probe consisted of a modified polythene tube armed with a stainless steel electrode $0.25 \mathrm{~mm}$ diameter projecting $1 \mathrm{~mm}$ through a side hole, and surrounded by a rubber cup (Fig. 1).

\section{ELECTRICAL ACTIVITY}

The electrode was sucked onto the bowel wall to a negative pressure of $20 \mathrm{~cm} \mathrm{Hg}$ so that the electrode penetrated the bowel to a depth of approximately $2 \mathrm{~mm}$. Adherence of the electrode was enhanced by the rubber cup (Monges and Salducci, 1970) which diminished the movement artefact when the bowel contracted vigorously. An indifferent electrode was placed on the scarified skin over the right iliac fossa in a position where the artefact of the electroReceived for publication 27 April 1972.

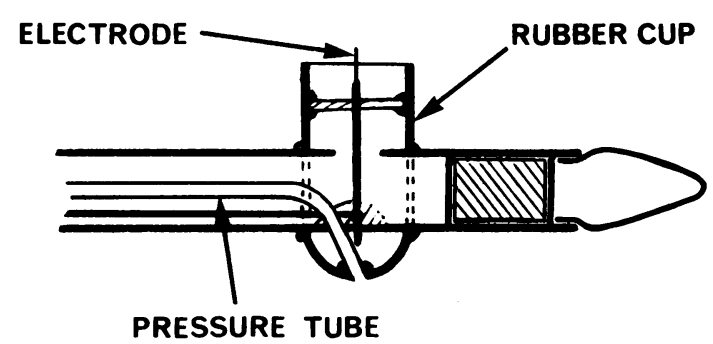

Fig. 1 The tip of the modified nasogastric tube used to record myoelectrical activity of the terminal ileum showing the spatial relationship of the electrical and pressure sensing devices.

cardiograph was minimal. Monopolar electrical records were fed to an ac amplifier with a frequency response within $\pm 3 \mathrm{~dB} 0.20 \mathrm{~Hz}$ to $1 \mathrm{~K} \mathrm{~Hz}$ and were displayed on ultraviolet paper at a sensitivity of $3 \mathrm{~cm} / \mathrm{mv}$. Parallel outputs from the amplifier were led to the recorder, one passing through an electrical filter, and both records were displayed simultaneously. The filter had a frequency range between 9 and $14 \mathrm{cycles} / \mathrm{min}(3 \mathrm{~dB} 0 \cdot 15$ and $0 \cdot 23 \mathrm{~Hz})$. In addition the electrical and motor waves were recorded on magnetic tape. Electrical activity is presented in terms of the frequency and amplitude of the large deflection known as the slow wave, or the pacesetter potential (PSP). Alternatively, this may be called the basic electrical rhythm (BER). Bursts of more rapid oscillations (action potentials) superimposed on the pacesetter potential were observed in relation to motor waves and the number of such bursts was counted. 


\section{MOTOR ACTIVITY}

An open-tipped catheter of $1 \mathrm{~mm}$ internal diameter was threaded along the modified polythene tube and was brought out opposite the electrode. The catheter was perfused with 0.15 molar saline at a rate of $10 \mathrm{ml} / \mathrm{hr}$ by a Palmer constant infusion pump. The proximal end of the catheter was connected to a strain gauge pressure transducer (SE 76/8). By this system intraluminal changes in pressure adjacent to the electrode were monitored. Motility is reported as the sum of the duration of individual pressure waves expressed as a percentage of the total recording time (percentage motility). The electrical record, raw and filtered, the motility wave, and the pneumogram were displayed on an ultraviolet recorder (SE 2000).

Patients were studied in a comfortable semirecumbent position on a couch in a warm environment during the morning after an overnight fast. The probe was passed $12 \mathrm{~cm}$ into the terminal ileum. Obstruction was not caused since gas and liquid were passed from the ileostomy during testing.

Six patients were tested under resting conditions one week after their operation (early test) and again between one month and six months later (delayed test).

Synthetic gastrin I in doses of $0 \cdot 1$ and $1 \mu \mathrm{g} / \mathrm{kg}-\mathrm{hr}$ (10 subjects) and secretin 0.25 and 1 unit $/ \mathrm{kg}-\mathrm{hr}$ (10 subjects) were infused at a constant rate. The dosage used was selected from dose-response studies using gastrin in doses $0 \cdot 01,0 \cdot 1,1,2,4$, and $8 \mu \mathrm{g} / \mathrm{kg}-\mathrm{hr}$ in two tests and secretin $0 \cdot 25,1,2,4$, and 8 units $/ \mathrm{kg}$ $\mathrm{hr}$ in two tests.

After intubation of the terminal ileum an intravenous infusion of saline was commenced and a record made over the ensuing 60 minutes. At this time if a humoral agent was to be used this was substituted for the saline and recordings were made over the following 60 minutes. In four patients extended control periods in which saline was infused for between two and four hours were observed. The total recording time in the 25 fasted patients was 30 hours with saline infusion, during gastrin $I$ infusion 11 hours, and during secretin infusion 10 hours.

In two patients undergoing cholecystectomy for gallstones implanted terminal ileal stainless steel subserosal electrodes were brought out through a drain in the right hypochondrium. Electrical records only were made under resting conditions from the third to the seventh postoperative day. The electrodes were then removed with the drain.

Twenty minutes were allowed for the increased activity consequent on intubation to pass before the record was used for analysis, Records on the ultraviolet paper were visually analysed. Data on the magnetic tape was processed using Biomac
1000 correlator. Auto- and cross-correlation functions were calculated.

\section{Results}

\section{RESTING STUDIES}

\section{Electrical records}

In 42 tests (total duration 30 hours) in fasted patients with established ileostomies the pacesetter potential had a frequency range of 6.5 to 9.3 cycles/ min (mean $8.85 \mathrm{c} / \mathrm{min} \pm 0.13$ ). The pacesetter potential was present throughout each test, and though the frequency varied \pm 0.2 cycles/minute from minute to minute, the mean frequency was the same for repeated tests (up to five) in any individual. The amplitude of the pacesetter potential waxed and waned during an individual recording with a range of 0.2 to $1.2 \mathrm{mv}$ (Fig. 2). It was maximal during the periods when action potentials were present. Action potentials were always accompanied by pressure waves and occurred at the commencement of the upstroke of the pressure wave (Fig. 3). Usually the action potentials were observed on the upstroke of the pacesetter potential. A third type of electrical wave was seen in three patients and this consisted of a slow change in potential over about 40 seconds. This was recorded for periods up to 20 minutes and the pacesetter potential was superimposed on it. In the two patients who had implanted serosal ileal electrodes, five recordings were made under resting conditions. In all tests action potentials and the pacesetter potential were recorded. The pacesetter potential frequency and the frequency of the bursts of action potentials were within the ranges obtained from the mucosal electrode in the ileostomists. The mucosal and serosal amplitude range of the pacesetter potential and the characteristic waxing and waning was not significantly different.

\section{Motor waves}

Motor waves were recorded in all patients. The resting percentage motility ranged from 5 to $55 \%$ (mean 30\%) in established ileostomists in the fasted state. There was a $20 \%$ change in spontaneous motility on day to day testing in seven patients who had more than one test more than six months after their operation.

\section{EARLY AND DELAYED TESTS}

In the six patients who had early and delayed tests there was no significant difference in the frequency of the pacesetter potential (Table I). The range of amplitude did not change significantly. There was a significant reduction in the frequency of action 


\section{I.V. Gastrin (1 $\mu \mathbf{g} / \mathbf{k g} . \mathbf{h r})$}

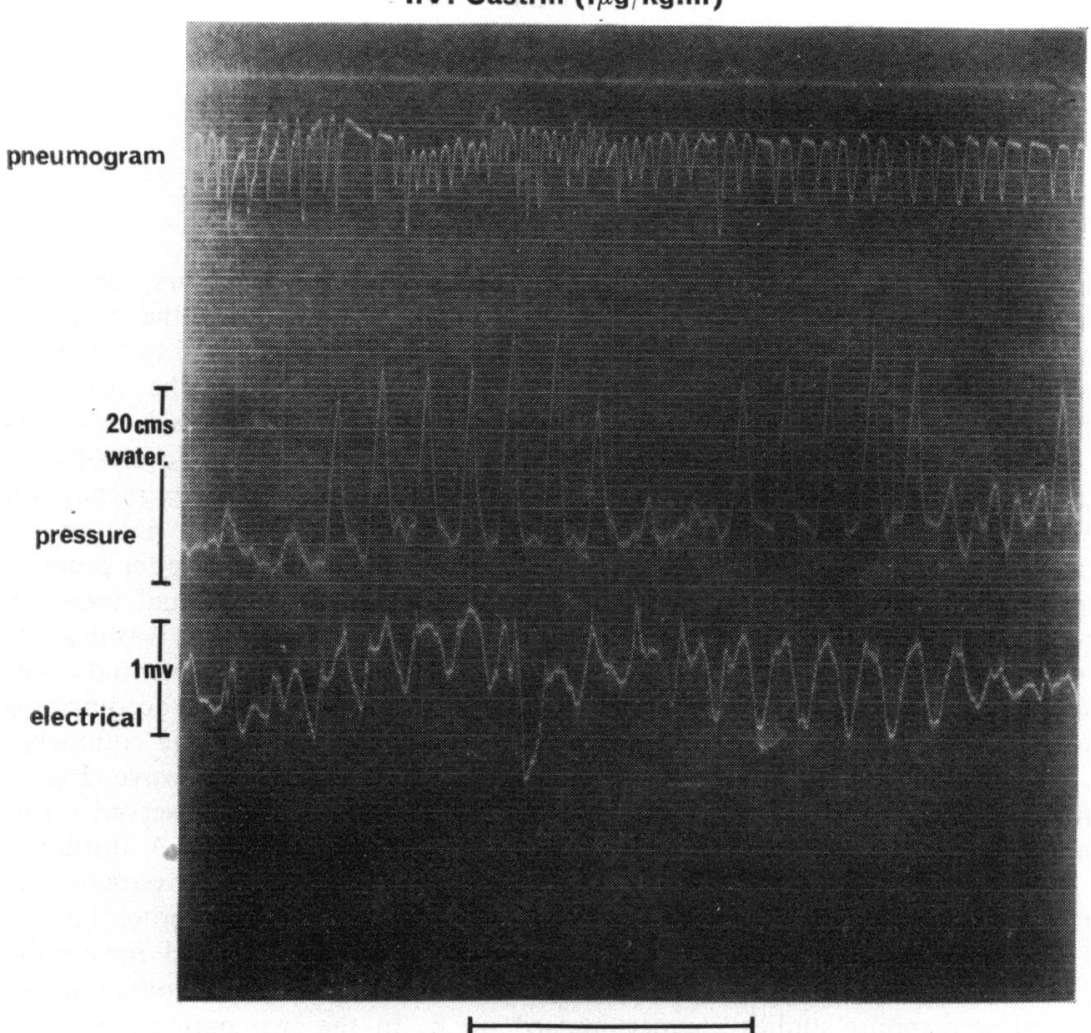

60 seconds

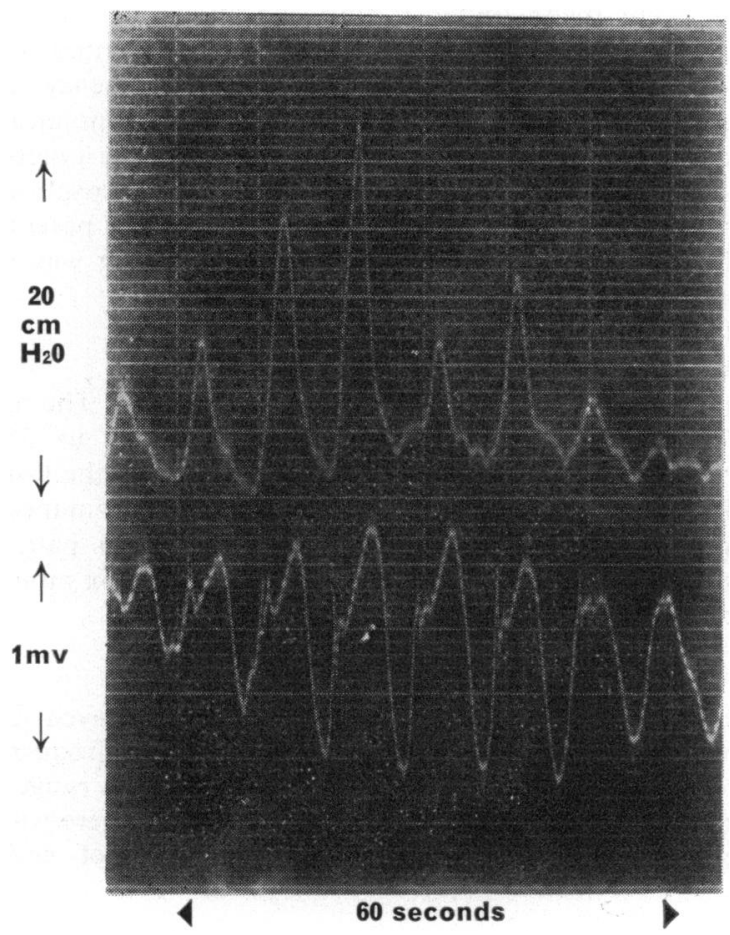

Fig. 2

Fig. 2 A record of the myoelectrical activity of the terminal ileum showing an exacerbation of pressure waves due to gastrin infusion.

Fig. 3 A detail of a record enlarged to show action potentials and their correspondence to the commencement of the upstroke of the pressure waves. The pressure wave is calibrated in $\mathrm{cm}$ of water and the electrical wave in millivolts.

Fig. 3 


\begin{tabular}{ll}
\hline Early & Delayed \\
\hline $9 \cdot 4$ & $9 \cdot 3$ \\
8.9 & $8 \cdot 8$ \\
9.0 & $9 \cdot 1$ \\
6.2 & $6 \cdot 2$ \\
8.8 & $8 \cdot 8$ \\
8.5 & $8 \cdot 5$ \\
\hline
\end{tabular}

Table I Ileal electrical activity (cycles per minute)

potentials in the delayed group. Concomitantly there was a significant reduction in the percentage motility (Fig. 4).

\section{INFUSION OF HORMONES}

\section{Control studies-electrical activity}

The five saline infusion control studies to the humoral investigations showed no significant shift in the pacesetter potential (maximum change 0.2 c/min.)

\section{Control studies-motor activity}

The change in percentage motility was less than $7 \%$ over consecutive 30 -minute periods.

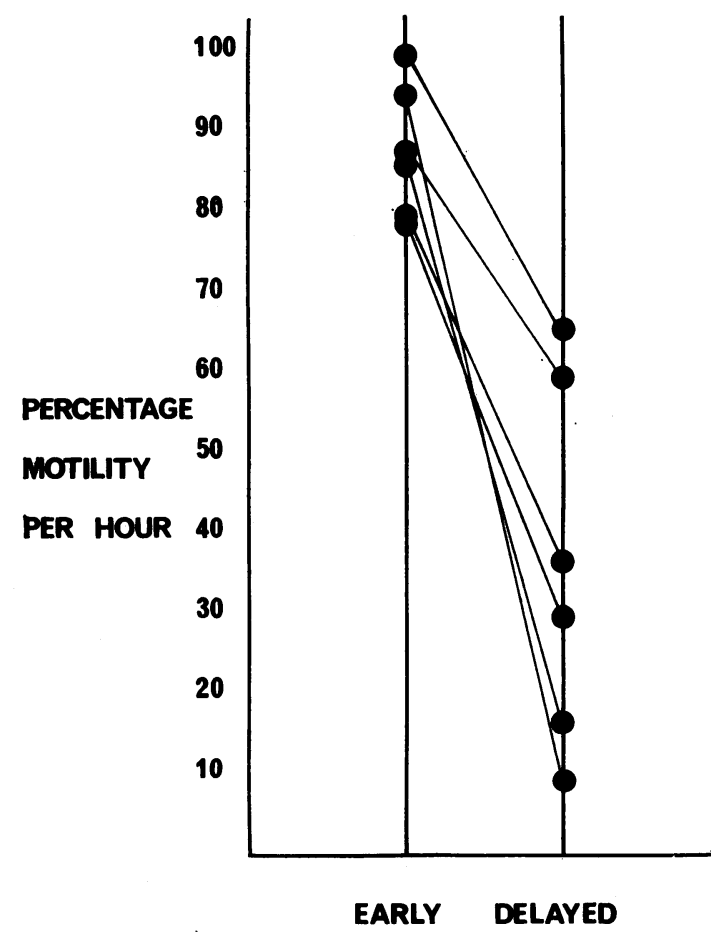

Fig. 4 The motility change in the terminal ileum which occurred with increasing time after panproctocolectomy.
Humoral studies-electrical activity

Dose response studies in two patients with gastrin I and two patients with secretin showed $1 \mu \mathrm{g} / \mathrm{kg}-\mathrm{hr}$ and 1 unit $/ \mathrm{kg}-\mathrm{hr}$ respectively produced maximal effect.

In the 20 patients studied by humoral infusion there was no significant change in configuration or frequency of the pacesetter potential (Tables II and III), with either gastrin I or secretin. However, gastrin I significantly increased the frequency of action potentials. Conversely, secretin infusion decreased significantly the frequency of action potentials.

\begin{tabular}{cl}
\hline Control & $\begin{array}{l}\text { Gastrin } \\
(1 \mu \mathrm{g} / \mathrm{kg} \text {-hr })\end{array}$ \\
\cline { 2 - 2 } $10 \cdot 0$ & $9 \cdot 8$ \\
$9 \cdot 1$ & $9 \cdot 2$ \\
$8 \cdot 8$ & $8 \cdot 8$ \\
$9 \cdot 1$ & $9 \cdot 1$ \\
8.9 & $8 \cdot 8$ \\
$9 \cdot 5$ & $9 \cdot 4$ \\
$9 \cdot 4$ & $9 \cdot 3$ \\
$6 \cdot 2$ & $6 \cdot 2$ \\
$9 \cdot 0$ & $9 \cdot 1$ \\
9.0 & 8.9 \\
\hline
\end{tabular}

Table II Ileal electrical activity (cycles per minute)

\begin{tabular}{ll}
\hline Controls & $\begin{array}{l}\text { Secretin } \\
\text { (1 unit/kg-hr) }\end{array}$ \\
\hline 9.9 & 9.7 \\
9.5 & 9.4 \\
8.3 & 8.4 \\
9.9 & 9.9 \\
9.3 & 9.3 \\
8.2 & 8.4 \\
8.3 & 8.3 \\
6.5 & 6.5 \\
8.5 & 8.5 \\
8.6 & 8.5 \\
\hline
\end{tabular}

Table III Ileal electrical activity (cycles per minute)

Humoral studies-motor waves

Gastrin I increased the percentage motility concomitantly with the increase in action potential frequency in eight out of 10 patients studied (Fig. 5). In one patient there was a signicant fall in the percentage motility and in one patient there was no significant change. Repeated testing in these two patients with the regular $1 \mu \mathrm{g} / \mathrm{kg}$-hr of gastrin I and with higher dosage failed to produce the characteristic increase in action potential frequency and motility.

In nine patients there was a significant decrease in motility during the infusion of secretin (Fig. 6). In only one patient who received secretin was there no significant motility change. 


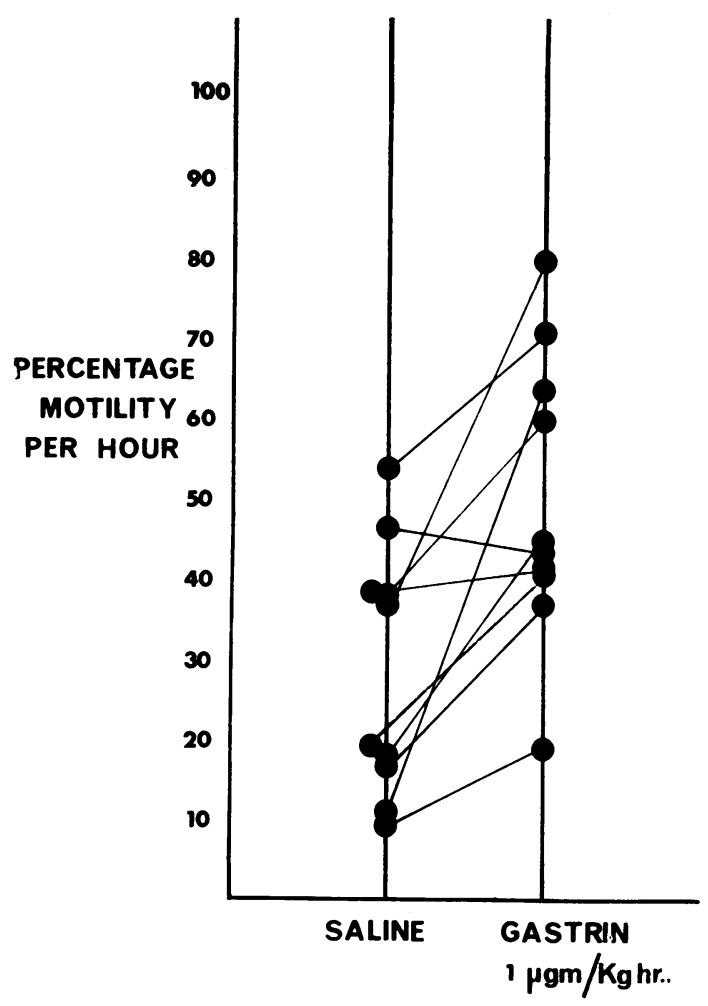

Fig. 5

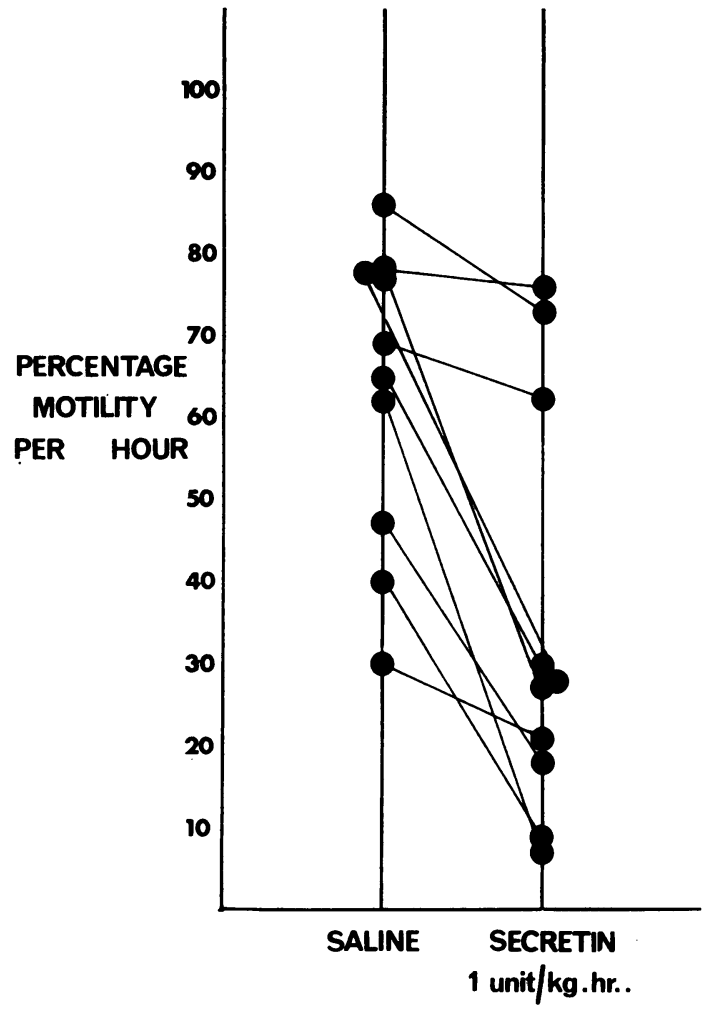

Fig. 6

Fig. 5 The percentage increase in motility which occurred in eight patients out of 10 during infusion with gastrin.

Fig. 6 The percentage decrease in motility that occurred in nine patients out of 10 during infusion with secretin.

\section{Discussion}

The amplitude and frequency of the pacesetter potential is entirely compatible with previous studies (Daniel, Carlow, Wachter, Sutherland, and Bogoch, 1958; Christensen, Schedl, and Clifton, 1966). The overall $30 \%$ spontaneous motility in the fasted state in the 25 patients studied is much lower than previously reported (Cummins, 1954; Code, Rogers, Schlegel, Hightower, and Bargen, 1957; Daniel et al, 1958) and this may be due to the non-obstructing effect of the open-tip catheter technique which enables resting activity to be recorded. The stability of the record was confirmed by the experiments in which saline was infused for three hours.

The clear correlation of action potentials with motility was made possible by the spatial relationship of the motor and electrical sensing devices. Daniel et al (1958) have shown that for action potentials to be demonstrably associated with contractions both must occur at the electrode. The open-tip catheter allows a recordable pressure change from an area little larger than, and at the same site as, the electrode. We have been unable to attribute a function to the slow waves lasting 40 seconds recorded in three patients.

The accommodative function of the terminal ileum following proctocolectomy is well known (Smiddy, Gregory, Smith, and Goligher, 1960). There is a reduction in the quantity of material evacuated from the stoma and the fluidity of the discharge is diminished. This change is highly advantageous preventing excessive loss of fluid and salt. We were stimulated to look for this change in terms of electrical activity and motility because this had not been demonstrated by previous studies (Code et al, 1957). The rapid change in consistency of the evacuate within the first 10 postoperative days led us to test our patients as soon as they were 
sufficiently recovered, usually at about one week. By the fourth postoperative week a significant change in action potential frequency and percentage motility had already taken place and this is a trend that probably continues until the terminal ileum is active for a mean $30 \%$ of the recording time. Whatever the mechanism responsible for the adaptive response it does not reside in the pacesetter potential, for this remains stable in the early and late studies. It is of the same order of frequency as in intact man as demonstrated by the records from the implanted electrodes. Subserosal electrodes recorded identical data to mucosal electrodes as has been shown in the stomach and duodenum in man (Kwong, Brown, Whittaker, and Duthie, 1971; Couturier, Roze, Paolaggi, and Debray, 1971). The adaptive change is brought about by a significant reduction in frequency of action potentials. This produces a corresponding reduction in the percentage motility. The reason for the decrease in the frequency of action potentials is unknown but it may originate in the autonomic innervation of the bowel, though Roth and Beams (1959) have shown that motility patterns in patients who had undergone vagotomy for duodenal ulcer were basically unchanged in the small bowel. Ganglion blocking and stimulating agents have been administered (McMahon, Code, Sauer, and Bargen, 1949; Cummins, 1954) and though electrical and motility changes have been produced in the small bowel in vivo the role of extrinsic neural tissue is not clear. Likewise the use of a variety of pharmacological agents such as morphine, epinephrine, and histamine (Daniel et al, 1958; Christensen, Schedl, and Clifton, 1964) has failed to clarify a control mechanism for the electromotility patterns in the small bowel.

Gastrin I and secretin were used to investigate the humoral control of electrical and motor activity of the ileum because of their relative purity and known reliability and in addition they were known to produce electrical and motor changes in the normal stomach (Kwong, Brown, Whittaker, and Duthie, 1971; Monges and Salducci, 1971). The pacesetter potential was noticeably resistant to the effect of both humoral agents in contrast to that of the stomach. However, the frequency of the bursts of action potentials was increased by gastrin I and decreased by secretin. It is probable that these hormones have a significant role in the control of small bowel motility by increasing or decreasing the frequency of action potentials.

Computer simulation of the electrical slow wave of the small bowel has been achieved by Nelsen and Becker (1968) and Sarna, Daniel, and Kingma (1971) using non-linear differential equations (Van der Pol and Van der Mark, 1928; Fitzhugh, 1961) and electronic relaxation oscillators. It was clear from both studies that the connexions or couplings between adjacent oscillators in addition to the oscillator parameters were of paramount importance in determining the characteristics of the electrical changes modelled by the oscillators. It is proposed that gastrin and secretin produce their effects by changing the coupling between the Nelsen oscillators modelling the electrical slow wave and the mechanical wave oscillator.

It is interesting to reflect on the possible significance of the effects of gastrin and secretin in intact man. Following the ingestion of food and during the gastric phase of digestion, gastrin released from the gastric antrum would tend to empty the small bowel ready to receive the gastric effluent. Small bowel digestion is aided by a decrease in the rate of advance of intraluminal content consequent on release of secretin when the meal reaches the duodenum. Whatever their exact role and the mechanism of action, gastrin and secretin have a significant effect in the electrical and motility pattern of the terminal ileum.

We acknowledge the support of the Medical Research Council for technical assistance.

\section{References}

Christensen, J., Schedl, H. P., and Clifton, J. A. (1964). The basic electrical rhythm of the duodenum in normal human subjects and in patients with thyroid disease. J. clin. Invest., 43, 16591667.

Christensen, J., Schedl, H. P., and Clifton, J. A. (1966). The small intestinal basic electrical rhythm (slow wave) frequency gradient in normal men and in patients with a variety of diseases. Gastroenterology, 50, 309-315.

Code, C. F., Rogers, A. D., Schlegel, J., Hightower, N. C., Jr., and Bargen, J. A. (1957). Motility patterns in the terminal ileum: studies in two patients with ulcerative colitis and ileac stomas. Gastroenterology, 32, 651-665.

Couturier, D., Roze, C., Paolaggi, J., and Debray, C. (1971). Electrical activity of the normal human stomach: a comparative study of recordings obtained from the serosal and mucosal sides. Rendic. R. Gastroenterol., 3, 130.

Cummins, A. J. (1954). Small intestinal function in patients with an ileostomy. Amer. J. Med., 16, 237-245.

Daniel, E. E., Carlow, D. R., Wachter, B. T., Sutherland, W. H., and Bogoch, A. (1959). Electrical activity of the small intestine. Gastroenterology, 37, 268-281.

Daniel, E. E., Wachter, B. T., Honour, A. J., and Bogoch, A. (1958). The relationship between electrical and mechanical activity of the small intestine in $\operatorname{dog}$ and man. Canad. J. Biochem., 38, 777-801.

Fitzhugh, R. (1961). Impulses and physiological states in theoretical models of nerve membrane. Biophys. J., 1, 445-446.

Kwong, N. K., Brown, B. H., Whittaker, G. E., and Duthie, H. L. (1970). Electrical activity of the gastric antrum in man. Brit. J. Surg., 57, 913-916.

Kwong, N. K., Brown, B. H., Whittaker, G. E., and Duthie, H. L. (1971). Response of the electrical activity, motor activity and acid secretion of the human stomach to pentagastrin and histamine stimulation. Scand. J. Gastroent., 6, 145-153.

McMahon, J. M., Code, C. F., Sauer, W. G., and Bargen, J. A. (1949). A study of the action of prostigmine on the bowel of human beings. Gastroenterology, 12, 970-977.

Monges, H., and Salducci, J. (1970). Etude électromyographique de la motricité duodénale chez l'homme normal. Arch. Mal. Appat. dig., 59, 19-28. 
Monges, H., and Salducci, J. (1971). Variations of basic electrical rhythm of the stomach in man produced by administration of pentagastrin and by introduction of water or nutritive substances into the stomach. Rendic. $R$. Gastroenterol., 3, 127-128.

Nelsen, T. S., and Becker, J. C. (1968). Simulation of the electrical and mechanical gradient of the small intestine. Amer. $J$. Physiol., 214, 749-757.

Roth, H. P., and Beams, A. J. (1959). The effect of vagotomy on the motility of the smal intestine. Gastroenterology, 36, 452-458.
Sarna, S. K., Daniel, E. E., and Kingma, Y. J. (1971). Simulation of the slow wave electrical activity of small intestine. Amer. J. Physiol., 221, 166-175.

Smiddy, F. G., Gregory, S. D., Smith, 1. B., and Goligher, J. C. (1960). Faecal loss of fluid, electrolytes and nitrogen before and after ileostomy. Lancet, 1, 14-19.

Van der Pol, B., and Van der Mark, J. (1928). The heart beat considered as a relaxation oscillator and an electrical model of the heart. Phil. Mag. Suppl., 6, 763-775. 